\title{
Journal of Parathyroid

\section{Abnormal parathyroid in some important tropical parasitic infections: a new trend}

\author{
Sora Yasri ${ }^{*}$, Viroj Wiwanitkit ${ }^{2}$
}

\begin{abstract}
The parathyroid disorder is an important problem in clinical endocrinology. There are several possible causes of parathyroid disorder. Infection is an uncommon cause of parathyroid disorder. The parasitic infection induced parathyroid disorder is an important problem in tropical medicine. In this paper, the authors briefly summarize and discuss on the important abnormalities of parathyroid due to important tropical parasitic infections.

Keywords: Parathyroid, Infection, Parasitic infections

Please cite this paper as: Yasri S, Wiwanitkit V. Abnormal parathyroid in some important tropical parasitic infections: a new trend. J Parathyr Dis. 2018;6(2):42-43. DOI: 10.15171/jpd.2018.16.

Copyright (๑) 2018 The Author(s); Published by Nickan Research Institute. This is an open-access article distributed under the terms of the Creative Commons Attribution License, which permits unrestricted use, distribution, and reproduction in any medium, provided the original work is properly cited.
\end{abstract}

\section{Introduction}

The parathyroid disorder is an important problem in clinical endocrinology. There are several possible causes of parathyroid disorder. Infection is an uncommon cause of parathyroid disorder. The parasitic infection induced parathyroid disorder is an important problem in tropical medicine. In this paper, the authors briefly summarize and discuss on the important abnormalities of parathyroid due to important tropical parasitic infections.

\section{Parathyroid disorder in cysticercosis}

Cysticercosis is an important tapeworm infection. This infection is an important food borne disease that can be seen in tropical countries worldwide. The disease can manifest as cystic lesion in any organs. For parathyroid glands, according to our best knowledge, there has never been any report on cysticercal cyst at parathyroid gland. Nevertheless, abnormal parathyroid function can be seen in case with cysticercosis. Basak et al discussed on an interesting case presenting with hypoparathyroidism according to neurocysticercosis (1). The case is due to the basal ganglion calcification due to cysticercosis (1). Basak et al concluded that "while adequate treatment of hypoparathyroidism may result to marked clinical improvement, serum concentration of calcium, phosphorus, and parathyroid hormone (PTH) is recommended to be established in all individuals with calcification of the basal ganglia to rule out hypoparathyroidism" (1).

\section{Parathyroid disorder in malaria}

Malaria is an important mosquito borne infection. The pathogenic plasmodium spp. parasite is the cause of the disease. The pathogen can affect the red blood cell and cause the acute febrile illness. In severe cases, death can be resulted. The effect of malaria on parathyroid has been mentioned for many years. David et al firstly reported on the observation on parathormone level in cases with malaria (2). David et al found that "the presence of depressed simultaneous serum parathormone (PTH) concentrations" $(2,3)$ in patients infected with malaria. Davis et al concluded on a decreased ionized calcium 'set point' for basal parathormone secretion but a normal parathormone response to acute hypocalcaemia in malaria" (4) and also noted that skeletal resistance may attenuate the impact of the parathormone response but individuals with malaria appear relatively resistant to the calcium chelating effects of citrated blood products (4).

Indeed, the hypocalcemia is an important mineral disorder in malaria and might relate with fatality. Accordingly Prabha et al concluded that hypocalcemia problem in malaria might be due to the parathyroid failure (5). St John et al found that parathyroid gland dysfunction was an important cause of hypocalcemia in severe malaria without acute renal failure (6). The underlying pathogenesis of parathyroid failure in malaria is still unknown. Nevertheless, in monkey model, the malaria can induce atrophy of parathyroid gland and disappearance of parathyroid cellular content (7).

\section{Parathyroid disorder in babeseosis}

Similar to malaria, babeseosis is another important tropical blood parasite infection. The parathyroid abnormality in babeseosis is very interesting. Nevertheless, there is a report on the PTH determination in infected horse (8). According to that study, there is no significant different of PTH level in cases with and without babeseosis (8). Hence, there should be no problem of abnormal parathyroid function in human babeseosis. Nevertheless, the exact situation required further study on clinical data on human infected cases.

\section{Parathyroid disorder in microsporidiosis}

Microsporidiosis is an important opportunistic infection in the patients with underlying immunodeficiency status. The 
Implication for health policy/practice/research/ medical education

There are many tropical infections that might have clinical interrelationship with abnormalities of parathyroid gland. The practitioners should recognize and keep in mind for investigation on those possible infections when they deal with unexplained parathyroid dysfunction.

involvement of the pathogen in visceral organ is possible. There is a recent report on detection of Trachipleistophora anthropophthera n. sp in parathyroid gland during autopsy of a case died from acquired immune deficiency syndrome (HIV/AIDS) (9). However, there is no specific data on clinical problem due to parathyroid microsporidiasis in that case (9).

\section{Parathyroid disorder in schistosomiasis}

Schistosomiasis is another important tropical parasite helminthic parasitic infection. The disease is known as blood fluke. There is a report on the PTH determination in infected dog (10). In that case, hypercalcemia and elevated PTH-related protein (PTHrP) due to schistosomiasis is reported (10). Since schistosomiasis is also a human infection, the similar problem of parathyroid disorder might be expected. The interrelationship between fascioliasis with or without schistosomiasis and osteoporotic manifestation has just been reported by Kilany et al (11). The interrelationship between abnormal PTH level and fascioliasis and schistosomiasis was hypothesized (11). This observation requires further studies for proof.

\section{Parathyroid disorder in fascioliasis}

Fascioliasis is an important fluke infection. The association between parathyroid disorder and fascioliasis has been proposed by Kilany et al (11). Indeed, there is a recent data from a study from a tropical medicine center in Thailand on PTH receptor - like member of family B1-protein couple receptors in the pathogen, Fasciola gigantica (http:// www.tm.mahidol.ac.th/seameo/2017-48-4/06-722523-762. pdf). It was summarized that the mentioned receptor might have a role in the regulation of calcium ion levels in the parasite, which might be the explanation for observation of abnormal parathyroid in infected cases.

\section{Parathyroid disorder in hookworm infection}

Hookworm is a common round worm infection. This infection can result in microcytic anemia and the problem is very common in several countries. Although there is no report on direct relationship between hookworm infection and parathyroid abnormality, the hookworm anemia can be a superimposed problem in the case with underlying renal failure who has abnormal PTH (12).

\section{Conclusion}

There are many tropical infections that might have clinical interrelationship with abnormalities of parathyroid gland. The practitioners should recognize and keep in mind for investigation on those possible infections when they deal with unexplained parathyroid dysfunction.

Conflicts of interest

The authors declare no conflicting interest.

Authors' contribution

SY and VW wrote the manuscript equally.

\section{Ethical considerations}

Ethical issues (including plagiarism, data fabrication, double publication) have been completely observed by the authors.

\section{Funding/Support}

None.

\section{References}

1. Basak RC. A case report of Basal Ganglia calcification - a rare finding of hypoparathyroidism. Oman Med J. 2009; 24:220-2.

2. Davis TM, Li GQ, Guo XB, Spencer JL, St John A. Serum ionized calcium, serum and intracellular phosphate, and serum parathormone concentrations in acute malaria. Trans R Soc Trop Med Hyg. 1993; 87:49-53.

3. Davis TM, Pukrittayakamee S, Woodhead JS, Holloway P, Chaivisuth B, White NJ. Calcium and phosphate metabolism in acute falciparum malaria. Clin Sci (Lond). 1991;81:297304.

4. Davis TM, Singh B, Choo KE, Ibrahim J, Sulaiman SA, Kadir ZA, Ismail R. Dynamic assessment of parathyroid function in acute malaria. J Intern Med. 1998;243:349-54.

5. Prabha MR, Pereira P, Chowta N, Hegde BM. Clinical implications of hypocalcemia in malaria. Indian J Med Res. 1998; 108:62-5.

6. St John A, Davis TM, Binh TQ, Thu LT, Dyer JR, Anh TK Mineral homoeostasis in acute renal failure complicating severe falciparum malaria. J Clin Endocrinol Metab. 1995; 80:2761-7.

7. Chen L1, Li G, Lu Y, Luo Z. Histopathological changes of Macaca mulatta infected with Plasmodium knowlesi. Chin Med J (Engl). 2001;114:1073-7.

8. Van Heerden J, Dauth J, Dreyer MJ, Nichas E, Marshall C, De Waal DT. Selected laboratory parameters of thoroughbreds. J S Afr Vet Assoc. 1990; 61:155-8.

9. Vávra J, Yachnis AT, Shadduck JA, Orenstein JM. Microsporidia of the genus Trachipleistophora--causative agents of human microsporidiosis: description of Trachipleistophora anthropophthera n. sp. (Protozoa: Microsporidia). Eukaryot Microbiol. 1998; 45:273-83.

10. Fradkin JM, Braniecki AM, Craig TM, Ramiro-Ibanez F, Rogers KS, Zoran DL. Elevated parathyroid hormonerelated protein and hypercalcemia in two dogs with schistosomiasis. J Am Anim Hosp Assoc. 2001; 37:349-55.

11. Kilany YF, Abou Holw SA, Abouel-Nour MF, Morsy AT. Early development of osteoporosis in male smokers with hypoandrogenism due to fascioliasis with or without schistosomiasis added by life style. J Egypt Soc Parasitol. 2009; 39:789-802.

12. Wu F, Xu Y, Xia M, Ying G, Shou Z. Hookworm Anemia in a Peritoneal Dialysis Patient in China. Korean J Parasitol. 2016; 54:315-7. doi: 10.3347/kjp.2016.54.3.3 